\title{
Development of Teacher Attitudes, Behaviors, and Skills Related to Elementary Science
}

\author{
Pascale Creek Pinner \\ Jan Ray \\ Hilo Intermediate School, Hilo, United States \\ University of Hawaii at Hilo, Hilo, United States

\begin{abstract}
Teacher attitudes, behaviors, and skills related to elementary science were developed using a T2T (teacher-to-teacher) PD (professional development) model. Participants in this study included teachers from three of nine elementary schools in the Hilo/Waiakea Complex Area in Hawaii. Both qualitative and quantitative findings from the participants suggested significant changes in teacher attitudes, behaviors, and skills related to elementary
\end{abstract} \\ science instruction in supporting PLCs (professional learning communities).
}

Keywords: professional development, teacher attitudes, elementary science, teacher science skills

\section{Introduction}

Conderman and Sheldon (2008) suggested that although science plays a central role in our world today, science instruction seems to be minimized, particularly at the elementary grade level. To cultivate higher-order thinking, as well as meet the changing demands of society, the quality and quantity of science teaching and learning must be increased in the elementary classroom. According to Abell and Lee (2008), the most effective professional development in science has: (1) relevant and applicable content directly connected to the classroom; (2) teachers learning in a way similar to the way their students will learn; (3) collaborative teacher relationships; and (4) sustained opportunities to collaborate and reflect over time (p. 62).

Researchers have investigated the construct of efficacy (Bandura, 1977, 2006; Riggs \& Enochs, 1990; Ramey-Gassert, Shroyer, \& Staver, 1996; Tschannen-Moran, Woolfolk Hoy, \& Hoy, 1998). Professional and conceptual development in teachers has also been explored (Gordon, 1990; Sheerer, 1997; E. M. Skaalvik \& S. Skaalvik, 2007). Supporting science content knowledge development, and effective science teaching, is imperative for elementary school teachers.

\section{Purpose of Study}

The purpose of this study was to examine the changes in self-efficacy elementary teachers experienced as they participated in the Frameworks for Success in Science Math/Science Partnership Title IIB T2T PD project. Specifically, this study focused on the identification and description of the changes in teachers' attitudes, behaviors and skills related to science instruction at the elementary level.

\section{Research Question}

One research question was posed for this study. How does a teacher's sense of self-efficacy (attitude)

Pascale Creek Pinner, Ph.D., Science Teacher, Hilo Intermediate School.

Jan Ray, Ed.D., Associate Professor of Education, University of Hawaii at Hilo. 
towards teaching elementary science change over a sustained period of professional development?

\section{Methods}

\section{Research Design}

This mixed-methods study used two research designs. The quantitative portion of the study used a one-group, post-test design with teacher participants. The qualitative portion of the study used a semi-structured interview protocol with a sub-sample of teacher participants.

\section{Subjects}

Eighteen teachers from three different elementary schools, who formed the first cohort of participants in the T2T PD project, were the subjects of this study. Sixteen of the teachers were female, and two of the teachers were male. All teachers were fully certified to teach at the elementary level. Eleven teachers held bachelor's degrees, and seven teachers held master's degrees. Teachers ranged from six to 27 years of teaching experience, with an average of 13.4 years.

\section{Instrumentation and Administration}

Research data were gathered in two ways for this study — first, through TRSEQ (the Teacher Retrospective Self-Efficacy Questionnaire) and, second, through participant interviews. Both instruments were administered to teacher at the conclusion of their second year of participation in the T2T PD program.

TRSEQ. The TRSEQ was developed through analyzing and adapting components of several existing surveys (Bleicher, 2004; Koehler, 2006; Tschannen-Moran et al., 1998; Woolfolk Hoy, 2000). Internal consistency reliability was addressed by the fact that all survey items represented only one construct - self-efficacy. Cronbach's alpha was used to calculate the reliability for the TRSEQ pre and post questions within the survey. Findings yielded a pre score of 0.921 and a post score of 0.951 , indicating very high instrument reliability. Two measures of validity were established - content validity and construct validity. TRSEQ items were adapted from already established surveys of teacher self-efficacy. The content was further adapted to reflect the behaviors and skills of elementary science teachers. Construct validity was addressed by including items that specifically described the behaviors and skills of self-efficacy in science teaching. The TRSEQ was administered to teachers during the summer after their second year of participation in the MPS T2T PD program.

Participant interviews. A SSIP (semi-structured interview protocol) was developed that addressed three broad categories-(1) efficacy and attitude towards teaching science; (2) the skills and behaviors needed to plan and teach science lessons; and (3) feelings about PLCs (professional learning communities). The interviews took 25-30 minutes to complete. Each interview was conducted in person. Interviews were audiotaped and transcribed for analysis. Threats to both descriptive and interpretive validity were addressed. Respondents were each given a copy of the transcript to check for accuracy, and an external auditor verified the transcripts with the audiotapes.

\section{Data Analysis}

Retrospective self-efficacy questionnaire pre/post data analysis. Since the sample size for Cohort I ( $n=$ 18) was smaller than the recommended size for parametric tests, a Wilcoxon signed-rank test was first conducted on the total pre and post scores for TRSEQ (see Table 1). 
Table 1

Wilcoxon Signed-Ranks Pre/Post TRSEQ

\begin{tabular}{ll}
\hline & Rpost Total-Rpre Total \\
\hline$Z$ & 3.726 \\
Asymp. Sig. (2-tailed) & 0.000 \\
\hline
\end{tabular}

Table 1 reveals a statistically significant increase in the total scores on TRSEQ following the T2T PD experience, $z=3.726, p<0.001$, with a medium effect size $(r=0.621)$. The median score increased from the pre-survey scores based on experience prior to the professional development $(M d n=23)$ to the post score based on their perceptions after completing two years of T2T professional development $(M d n=39.5)$.

In order to confirm the non-parametric results, a more robust paired samples $t$-test was conducted with the totals for the pre and post responses ( $M$ pre $=25.22, S D=6.5, M$ post $=40.4, S D=4.97$ ) (see Table 2). There was a significant increase in the total scores for TRSEQ pre score $(M=25.2, S D=6.5)$ and post score $(M=$ 40.4, $S D=4.9$ ) conditions $t=10.6, p<0.01$.

Table 2

Paired Samples t-Test-Pre/Post TRSEQ

\begin{tabular}{|c|c|c|c|c|c|c|c|}
\hline & \multicolumn{7}{|c|}{ Paired differences } \\
\hline & \multirow[t]{2}{*}{ Mean } & \multirow[t]{2}{*}{$S D$} & \multirow{2}{*}{$\begin{array}{l}\text { Std. } \\
\text { Error Mean }\end{array}$} & \multicolumn{2}{|c|}{$\begin{array}{l}\text { 95\% Confidence interval of the } \\
\text { difference }\end{array}$} & \multirow[t]{2}{*}{$d f$} & \multirow{2}{*}{$\begin{array}{l}\text { Sig. } \\
\text { (2-tailed) }\end{array}$} \\
\hline & & & & Lower & Upper & & \\
\hline $\begin{array}{l}\text { Rpost Total-Rpre } \\
\text { Total }\end{array}$ & 15.222 & 6.093 & 1.436 & 12.192 & 18.252 & 10.60017 & 0.000 \\
\hline
\end{tabular}

Participant interviews. Three broad categories of questions were explored through the participant interviews. They were: (1) efficacy and attitude towards teaching science; (2) the skills and behaviors needed to plan and teach science lessons; and (3) feelings about PLCs. Five of the 18 teachers were interviewed. The five teachers were purposely selected from different grade levels (grades K-6), with at least one teacher selected from each of the three participating schools. Further, in order to assure a diverse representation of teachers, ethnicities and years of experience were also considered.

Analyzing transcripts and unitizing. All interview audiotapes were transcribed to electronic documents. Then the coding scheme for interviews of teachers was developed in order to analyze the interviews.

Through content analysis of the interview transcripts, categories emerged. They included discussion related to:

(1) educational background;

(2) prior science experiences;

(3) current science experiences;

(4) feelings about current science lessons;

(5) feelings about the grade-level PLC;

(6) lesson prep skills;

(7) lesson "habits of mind";

(8) science lesson examples;

(9) changes to lesson examples;

(10) success of lessons; 


\section{(11) PLC configuration;}

(12) feelings about peers.

Each category was determined to be complete when both "internal homogeneity and external heterogeneity" criteria were met (Patton, 2002, p. 465).

After reviewing and placing categories within quadrants, the process of saliency analysis (Buetow, 2010) was completed. As can be seen in Table 3, the categories were placed into one of four quadrants: (1) highly important and recurrent; (2) highly important but not recurrent; (3) not highly important but recurrent; and (4) neither highly important nor recurrent.

Table 3

Saliency Analysis of Teacher Interviews

\begin{tabular}{|l|l|}
\hline Quadrant 1 & Quadrant 2 \\
Highly important and recurrent & Highly important but not recurrent \\
\hline Sciences experiences & Professional growth \\
PLC support & Teacher learning the science first \\
Time to prepare/understand lessons & Teachers teaching teachers \\
Student engagement & Older teachers learning new tricks \\
\hline Quadrant 3 & Quadrant 4 \\
Not highly important but recurrent & Neither highly important nor recurrent \\
\hline Organization (binders, material prep) & Educational background \\
Collaboration/sharing & Use of SMART boards \\
Revisions/extension of lessons & \\
Cooperative learning & \\
Hands-on & \\
Differentiation & \\
Integration & \\
Science tools/materials used & \\
\hline
\end{tabular}

Once the saliency analysis using quadrants was completed, major themes were identified. The Quadrant 1: Highly important and recurrent themes that emerged included: (1) impact of science experiences; (2) impact of grade-level PLCs; (3) time; and (4) student engagement. It became apparent that most of what was placed in Quadrant 2 could also be categorized within the themes developed above, except (5) professional growth, which became the fifth major theme. Each of the items in quadrant three supported the four major themes described above and thus did not provide any additional themes.

\section{Limitations}

There were three limitations identified for this research study. First, there were a small number of participants (18) who participated in this study. Consequently, generalizability of the data to larger populations would be limited. Second, participating teachers were self-selected for the project and, therefore, self-selected for this research study as well. Finally, this research was not a randomized controlled trial study because the T2T model is still under development, and the resources were not available for testing effectiveness via a larger experimental study.

\section{Results and Discussion}

\section{TRSEQ}

TRSEQ was used to determine how the teachers perceived their changes in self-efficacy over the first two years of the T2T PD project. According to the data, there were statistically significant positive changes from 
the pre to the post total score on the survey. The pre $(M=2.5)$ indicated the average answer choice of "Very little" to "Some" for the teacher's perceived sense of efficacy prior to participating in the study. The post ( $M=$ 40.4) total score indicated an average response of "Quite a bit" for the survey, with two of the 18 teachers selecting "A great deal" as their primary response. The data from the parametric and non-parametric tests suggest that teachers reported they were feeling more confident and doing more science in their classrooms after participating in the project over the past two years.

\section{Participant Interviews}

The differences between how teachers felt before and after participating in the T2T PD project were shared during the interviews. The word "confident" appeared multiple times in all five interviews, as did positive descriptors like "supported", "successful", "accomplished", "significant", and "reflective". The teachers also emphasized that they enjoyed the sharing that occurred in their regular PLC meetings, as well as the support they received. Overall, the interview themes suggested that the teachers believed the T2T PD model used in their grade-level PLCs allowed for substantial professional growth in science teaching and learning.

Prior to the project, three of the five teachers stated that they did not have positive science experiences. One teacher shared, "So one of my (prior experiences) was taking a science class. It was astronomy. It was Astronomy 101. It was at the University of Hawaii at Manoa, and it was just one of my harder classes in my whole educational career. Just taking the class and understanding the concepts and just struggling with that kind of class ..."

A second teacher shared that she did not have positive experiences in science. She stated that one of her classes at the University of Hawaii at Hilo "did not prepare" her to teach in her own classroom. "I never had very good experiences in science. (They) were not positive. They were negative". In addition, her experiences were mostly paper/pencil and "very boring"- - both as a student and as a teacher with her first students.

The third teacher stated that she "wasn't that into science" because her experiences were “ $\ldots$ at times intimidating. Some of the astronomy was just overwhelming. The chemistry I took as a summer course, and that was intense". However, this teacher did end by saying that her experiences "overall (were) positive" due to having several classes with hands-on experiences to augment the textbook.

In contrast to the past, current science experiences were more positive in tone. Two of the teachers stated that they "learned a lot" over the last two years in the T2T PD project. One teacher shared, "... over (the) years with, I feel really comfortable. I feel prepared. I know I have more knowledge now, and when I do science with the kids, they're more excited because I know how to better teach science".

Additionally, teachers shared that they became more organized, excited, and comfortable with the science content and pedagogy that they developed and implemented. One teacher commented, "I've learned a lot, and I've also gotten really organized with science. I feel like Ms. Frizzle with lots of growth (when) doing hands-on science experiences. I've really had a lot of growth because there're a lot of things I wouldn't have done if I didn't participate, mainly a lot of hands-on, I guess, because, like I said, in college they taught (using) pencil/paper".

The word "confident" appeared repeatedly throughout two of the five teachers' interviews. As one teacher explained, "I think for me, my teaching of science changed. Within myself, I feel more comfortable, more knowledgeable and more confident in the science curriculum. And when a teacher feels more comfortable and more knowledgeable, students will have an easier time understanding what you're trying to teach them". 
When questioned about how she feels about science after participating in the T2T PD project, one teacher stated that she is better at teaching science. Prior to the project, she did "activities and fun" but didn't really teach science. Now, she feels that she is able to meet the kids where they are and take them to the next level by setting the stage and facilitating their science learning. Two key words described her current feelings towards science-accomplished and significant. She also stated, "I really get (into) science now that I've been participating in the grant. I can kinda build on what they know and I just... (meet) the kids where they're at and (take) them to the next level".

Throughout the interviews, it was evident that science teacher self-efficacy improved through teacher participation in the T2T PD project.

\section{Conclusion}

The results indicated that teachers felt supported by T2T PD model in both physical and social ways. All of their responses aligned with what Bolman and Deal (2008) address as the structural frame- the one that looks at the "social architecture of work" (p. 106).

This study reinforced the idea that teachers grow and develop over time. The prior literature only described, in a limited way, what efficacy looks like at one moment in time (Bandura, 1977, 2006; Riggs \& Enochs, 1990; Ramey-Gassert et al., 1996; Tschannen-Moran et al., 1998). When teachers are supported by the T2T PD model over a two- or three-year period, they do learn more than basic science content because they begin to internalize and implement science experiences for their students that are deeper and more engaging than those simple activities they did in the past (if they even taught science). In addition, as they continue to learn and become more confident, they also recognize what they have not quite understood and they move towards trying to improve in those areas; they now know what they don't know, so they can learn more about it, which in turn will support their identification and addressing of misconceptions in their student's learning. Finally, as the teachers move towards a higher sense of efficacy, their feelings towards learning challenging material or experiments changes to a "can do" attitude, and they take on the challenge of learning and teaching new skills.

Finally, the ability to take this professional development model and use it to help teachers with the Common Core Standards needs to be explored. There needs to be a way to support teachers and schools through the T2T PD model to continually improve teaching and learning.

\section{References}

Abell, S. K., \& Lee, M. H. (2008). Perspectives: Research and tips to support science education. Science and Children, 62-63.

Bandura, A. (1977). Self-efficacy: Toward a unifying theory of behavioral change. Psychological Review, 84, 191-215.

Bandura, A. (2006). Adolescent development from an agentic perspective. In F. Pajares, \& T. Urdan (Eds.), Self-efficacy beliefs of adolescents (pp. 1-43). Greenwich, C.T.: Information Age.

Bleicher, R. E. (2004). Revisiting the STEBI-B: Measuring self-efficacy in preservice elementary teachers. School Science and Mathematics, 104(8), 383-391.

Bolman, L. G., \& Deal, T. E. (2008). Reframing organizations: Artistry, choice and leadership (4th ed.). San Francisco, C.A.: John Wiley \& Sons, Inc.

Buetow, S. (April 2010). Thematic analysis and its reconceptualization as "saliency analysis". Journal of Health Services Research \& Policy, 15(2), 123-125. Retrieved from http://jhsrp.rsmjournals.com/content/15/2/123.full

Conderman, G., \& Sheldon Woods, C. (Winter, 2008). Science instruction: An endangered species. Kappa Delta Pi Record, 76-80. 
Gordon, S. P. (1990). Developmental supervision: An exploratory study of a promising model. Journal of Curriculum and Supervision, 5(4), 293-307.

Koehler, J. R. (2006). The measurement of teacher efficacy. A poster presentation at the Harvard Graduate School of Education Student Research Conference and International Forum.

Patton, M. Q. (2002). Qualitative research \& evaluation methods (3rd ed.) Thousand Oaks, C.A.: Sage Publications.

Ramey-Gassert, I., Shroyer, M. G., \& Staver, J. R. (1996). A qualitative study of factors influencing science teaching self-efficacy of elementary level teachers. Science Education, 80(3), 282-315.

Riggs, C. M., \& Enochs, L. G. (1990). Toward the development of an elementary teacher's science teaching efficacy belief instrument. Science Education, 74(6), 625-637.

Sheerer, M. (1997). Using individualization and scaffolding to improve inservice programs. Early Childhood Education Journal, 24(3), 201-203.

Skaalvik, E. M., \& Skaalvik, S. (2007). Dimensions of teacher self-efficacy and relations with strain factors, perceived collective teacher efficacy, and teacher burnout. Journal of Educational Psychology, 99(3), 611-625.

Tschannen-Moran, M., Woolfolk Hoy, A., \& Hoy, W. K. (1998). Teacher efficacy: Its meaning and measure. Review of Educational Research, 68(2), 202-248.

Woolfolk Hoy, A. (April 28, 2000). Changes in teacher efficacy during the early years of teaching. Paper presented at the Annual Meeting of the American Educational Research Association, New Orleans, L.A. 